\title{
The Recent Progresses in Industrial Centrifugal Compressor Designs
}

\author{
Dingkun Liang, Hanqian Yang*, Cheng Xu, Yandan Jiang, Zhongwei Yi \\ Department of Mechanical and Electrical Engineering, Central South University of Forestry and Technology, Changsha, China
}

Email address:

yhanqian@sina.com (Hanqian Yang)

${ }^{*}$ Corresponding author

To cite this article:

Dingkun Liang, Hanqian Yang, Cheng Xu, Yandan Jiang, Zhongwei Yi. The Recent Progresses in Industrial Centrifugal Compressor Designs. International Journal of Fluid Mechanics \& Thermal Sciences. Special Issue: Fluid Mechanics \& Thermal Sciences in Turbomachines.

Vol. 6, No. 2, 2020, pp. 61-69. doi: 10.11648/j.ijfmts.20200602.13

Received: May 17, 2020; Accepted: May 28, 2020; Published: June 28, 2020

\begin{abstract}
The centrifugal compressor has been widely used in low power gas turbine, supercharger and industrial turbine compressors. Due to its outstanding advantages of simple process, compact structure and wide working range, it is more advantageous in some aspects such as small flow range than counterparts. However, the design of important components of centrifugal compressor requires lots of design experience and consideration. Because of the deepening research of the industrial centrifugal compressor, some excellent design optimization methods and experiences are obtained from researchers. In order to enable designers to get the preliminary design parameters and to develop a compressor with better performance better and faster, this paper addresses the main design optimization methods and design experiences of the components of the industrial centrifugal compressor. The detailed design considerations and design process for centrifugal compressor can reduce the design cycle time without scarifying performance for the new design. The purpose of this paper is to provide some design considerations and experiences of the centrifugal compressor for researchers. According to the centrifugal compressor design optimization process, purposed considerations in this paper are useful for compressor preliminary parameters selections. The optimizations and design considerations in this paper provide a detailed reference document for future centrifugal compressor developments.
\end{abstract}

Keywords: Centrifugal Compressor, Design Optimization Methods, Design Considerations and Experiences

\section{Introduction}

With the advances of technology and the needs of industrial production for the past few years, the centrifugal compressor is widely used in the field of aerospace, auto industry, petrochemical industry and so on, which is because of its high reliability, small size and other advantages. The pressure ratio and efficiency of the single centrifugal compressor shows a trend of increasing and the efficiency loss of all components of the centrifugal compressor got extensively optimized. Moreover, the improvement and optimization of the industrial centrifugal compressor design has become one of the hot topics in the turbomachinery area thanks to the development of CFD technology. Although the design process has been greatly simplified for the industry centrifugal compressor in using existing design tools, there are also enormous difficulties that should be considered. Because of the complexity of flow, matching requirements of multiple conditions and structural constraints, the perfect design and great performance of a centrifugal compressor does not only rely on simple estimation or a certain optimization of the component, but also needs to iterate some important consideration. In the whole design process, one-dimensional dynamics design, three-dimensional modelling design, CFD numerical simulation and other works should be applied by commercial software to assure the stability and high performance.

In recent years, the centrifugal compressor is also developing rapidly in the direction of larger impeller diameter, higher impeller flow coefficient, wider and larger efficient function range, higher single-stage pressure ratio, lower leakage ratio, higher aerodynamic efficiency, more standardized components and so on. However, there are still some problems in the study of the centrifugal compressor which researchers need to solve. Computational Fluid Dynamics (CFD) tools have been 
widely used to optimize the impeller, diffuser and volute designs. The main application of the CFD focuses on the analysis of efficiency of turbine and compressor, whether the compressor's overall operating range can meet the design requirements. The main aerodynamic problems of multistage compressor and turbine are whether the compressor's overall operating range and efficiency can meet the design requirements and all stages' flow are matched. After preliminary design parameters are selected, including inlet and outlet diameter or trim number, blade outlet angle, tip clearance and so on, computational fluid dynamics tools can complete more detailed design. Inlet distortion and impeller cornerite has a great influence on the performance of the whole compressor machine. So changing the shape of the inlet chamber and the size of impeller cornerite plays an important role in optimizing the internal flow. Different bending forms of impeller will make flow conditions inside the impeller change. Experimental investigation of different blade outlet angles will also optimize the performance curve of the compressor. And it is well known that the rotor tip clearance flow has profound effects on the performance and stability of axial compressors. Under different flow conditions, the top clearance will have different effects on the stage efficiency. The existing papers emphasize the research for some variables of a certain component or multi-part matching problem, which does not comprehend all the factors of performance. Therefore this paper will introduce the influence factors in the optimization process and some research progress.

\section{The Factors Affecting the Centrifugal Compressor}

Presently, Three-dimensional design methods don't become mainstream tools for the centrifugal compressor, although the numerical computation and computer-aided design software have been making great progress. In the initial design process of a centrifugal compressor, one-dimensional liner and two-dimensional flow optimization tools are most important for the designer. The most important aerodynamic components including inlet, inlet guide vanes, impeller, diffuser, return channel, volute and sidestream significantly influence the total efficiency and performance of the centrifugal compressor. The aerodynamic design procedures for industrial centrifugal compressor are discussed by $\mathrm{Xu}$ [1]. A new design process is discussed in the paper. To fine an optimal geometry of compressor, the design parameters of the impeller, diffuser and volute are optimized by the meanline tool before the three-dimensional CFD optimization and the shape of the blades, flow channels and so on are modified. The detailed proposal design process is shown in figure 1. There are lots of researches on these components. The components will be discussed in order according to the importance.

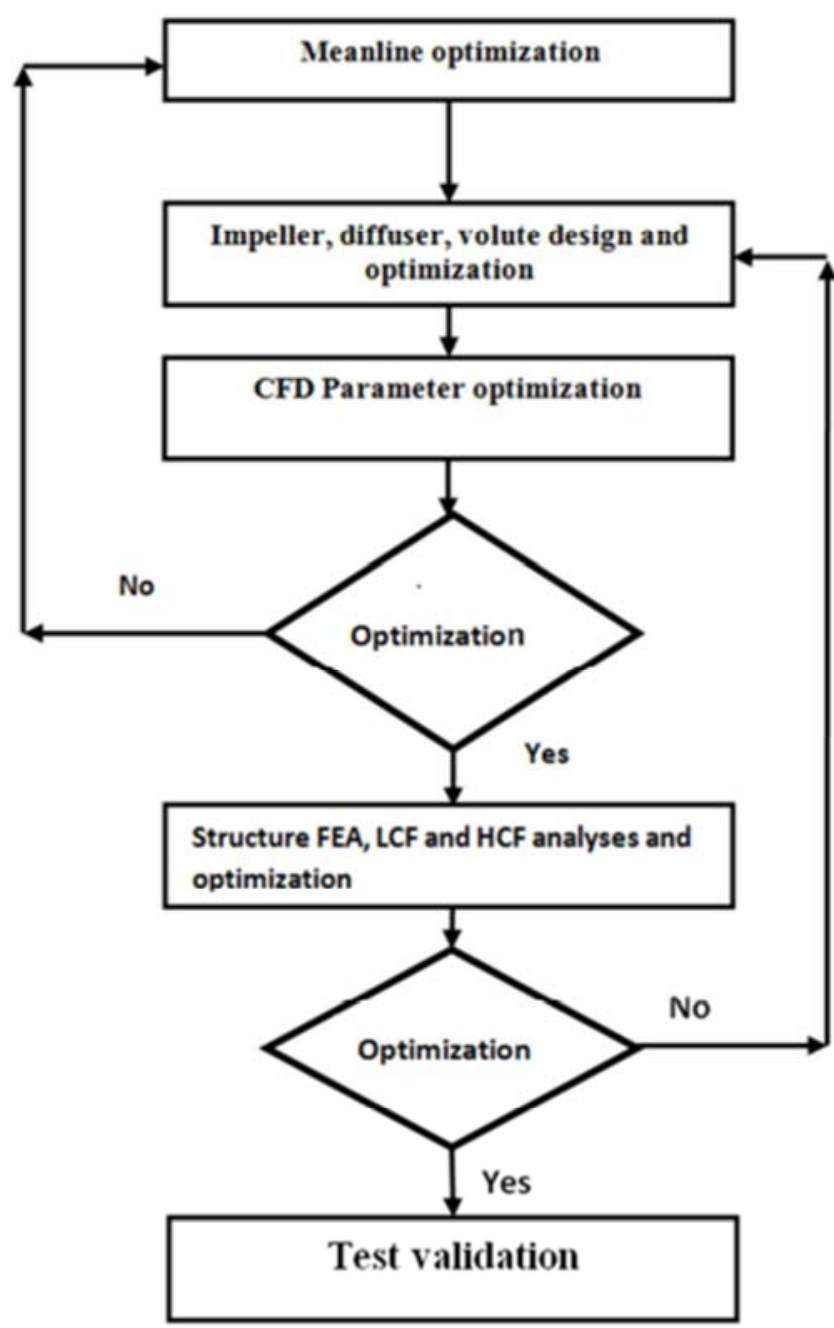

Figure 1. Centrifugal compressor design optimization process.

\subsection{Impeller}

In the optimization of centrifugal compressors, the quality of the impeller optimization will play a decisive role in the compressor stage performance. The impeller is the only component of the compressor which applies work to the gas. When the gas flows through the impeller, the gas will be subjected to centrifugal force. The pressure and velocity of the gas will enhance when they leave the impeller. The purpose of the impeller optimization is to obtain a larger energy head as possible as well as to increase the compressor operating range. Another target for the impeller optimization is to decrease the manufacturing cost. The impeller needs to satisfy the manufacturing technology and is easy to process. Reduce the manufacturing cost as much as possible under the premise of satisfying the use requirements. And the flow development inside the impeller not only determines the dynamics efficiency of itself but also strongly influences the efficiency of the diffuser. Researchers at home and abroad consider that some geometric parameters will affect the performance of the impeller through the study of the impeller and the main research include blade angle distribution, meridian channel shape, blade thickness distribution and tip clearance and so on. The optimization of the one-dimensional design parameters 
for the blade is an important part to increase the efficiency and performance of impeller. And blade angle distribution, meridian channel shape, blade thickness distribution should be taken into consideration.

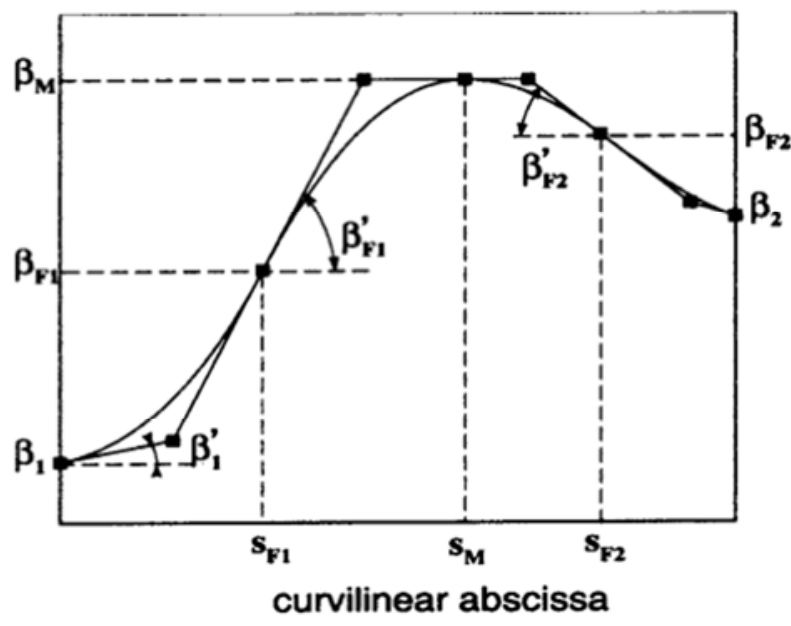

Figure 2. Blade angle distribution parameterization.

The blade angle distribution is the most important parameter of the centrifugal compressor blade and it directly links to the final shape of the blade. The blade angle is generally calculated based on the aerodynamics parameters. But the optimal solution needs to be obtained from iteration. If researchers can find out the mechanism of blade Angle affecting impeller performance and adjust the product to a reasonable blade angle distribution, the accuracy of iterative calculation can be greatly improved. Duccio [2] gave up an optimized blade angle distribution at the blade tip of a centrifugal impeller. And this kind of distribution can be described by the Bezier curve, showen as figure 2, which uses the blade inlet angle $\beta_{1}$, the blade outlet angle $\beta_{2}$, the maximum value of the blade angle $\beta_{\mathrm{M}}$ and two flex points as the control points. He concluded that changing the blade angle of blade root and tip has little effect on the centrifugal impeller and changing the distribution of blade inlet angle at tip has great influence on the centrifugal compressor. If the blade Angle distribution is not reasonable, the maximum efficiency of the impeller will be reduced by $5 \%$. But changing distribution of the blade outlet angle is of little influence for the impeller performance. Kim, S. [3] designed four blades with different blade angle distributions and analysed the flow physics inside each impeller in his paper. He wants to explain the relationship between blade angle distribution and the flow characteristics, loss generation, and the performance of these impellers. The results indicate the wall skin friction loss increases as the variation of blade angle increases because the increase in the blade surface area. The blade which has small variation of blade angle, is relatively radial, tends to exhibit high blade loading loss and tip clearance loss, whereas the blade, which has a larger blade turning, raises a high wall skin friction loss and a hub-to-shroud loading loss. Chen [4] further discussed the influence mechanism of blade angle distribution at tip inlet on the impeller based on the numerical simulation of tip blade angle distribution of transonic blade. The importance of the control curve for the tip blade angle distribution is explained. Meanwhile, a good adjustment method for the tip blade angle distribution is given that controlling the degree to which the curvature of the suction surface at the tip inlet decreases and the length of the low-curvature segment, the two acceleration of the splitter blades on the suction surface can be avoided, and the shock waves on the suction surface can be fused with the compression waves emitted from the leading edge of the blade.

At present, there are not many studies on meridional passage at home and abroad. For the flow passage design of impeller, the combination of a straight line and a multi-section curve composed of one or two arcs are usually adapted to replace the axial plane streamline of the front and rear cover plates of the impeller. This design method is convenient and simple and the zero-curvature can be achieved at line segments. But this method has some shortcomings that at the cornering point of curvature discontinuity the reverse pressure gradient along the flow direction will appear a maximum value, and the boundary layer is easy to separate, so the flow loss will increase greatly. Hence the better way is to use a curve to represent respectively meridian flow passage hub and contour. After referring to many literatures, Bezier line is the best choice for the meridian flow passage design. Doccio [2] has done a lot of research in this aspect. He gave a plan of the optimal hub and shroud meridional contours. It's ascertained by a second-order Bezier curve and endpoint of import and export. The figure 3 is the diagram of the plan. As we can see, the region between the two red points is the moving internal of the intermediate point of the Bezier curve. And we can adjust the total line as soon as the location of the intermediate point is adjusted. Unfortunately, the certain method of deciding the region has not been given in his paper. Wang $[5,6]$ provides a new method to design meridional passage. This method uses four points and three times rational Bezier curve to construct the flow line of the hub. The shape of meridional flow can be optimized by reasonable setting up factors and controlling points. The changing law of the geometrical shape of flow passage and the area of cross section can be changed flexibly. He also gave another design method which is using three times B-spline curves to generate a flow line of hubs. And the obtained design meridional channel is made to conform with the given $\mathrm{Fp} \sim \mathrm{L}$ curve. He presents a method to approximate the envelope of the cluster of the tangent circle with two adjacent tangent lines which is easy to understand and has great computational accuracy. $\mathrm{Xu}$ [7] introduced, in his paper, that reasonable design of inlet and outlet of meridian surface can improve the overall efficiency of compressor and reduce the sensitivity of blade tip clearance. The meridional flow channel shape of inlet and exit similar to Design 1, which is described in figure 5, has been demonstrated to improve the flow field near the impeller shroud and improve the total efficiency of impeller. The detailed design methods is not described in the paper but the study results provided important research contents for the meridional surface characteristics of 
centrifugal impeller design.

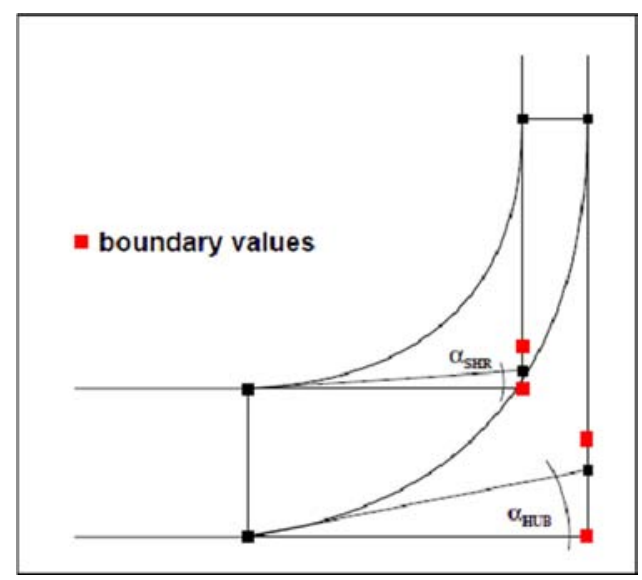

Figure 3. A meridional passage based on Bezier curve.

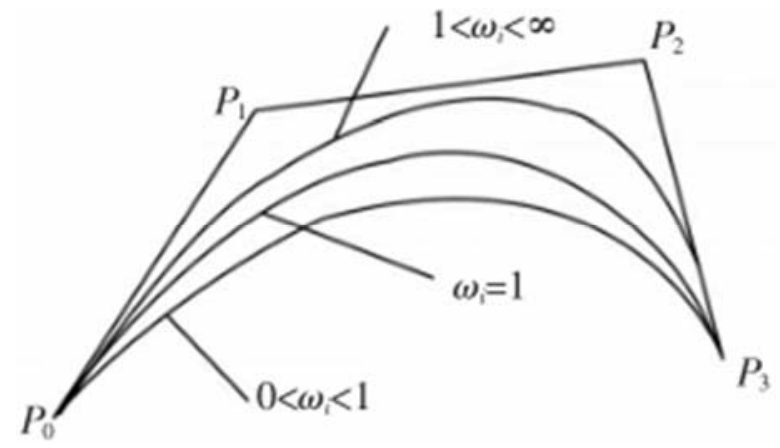

Figure 4. Three times rational Bezier curve and control polygon.

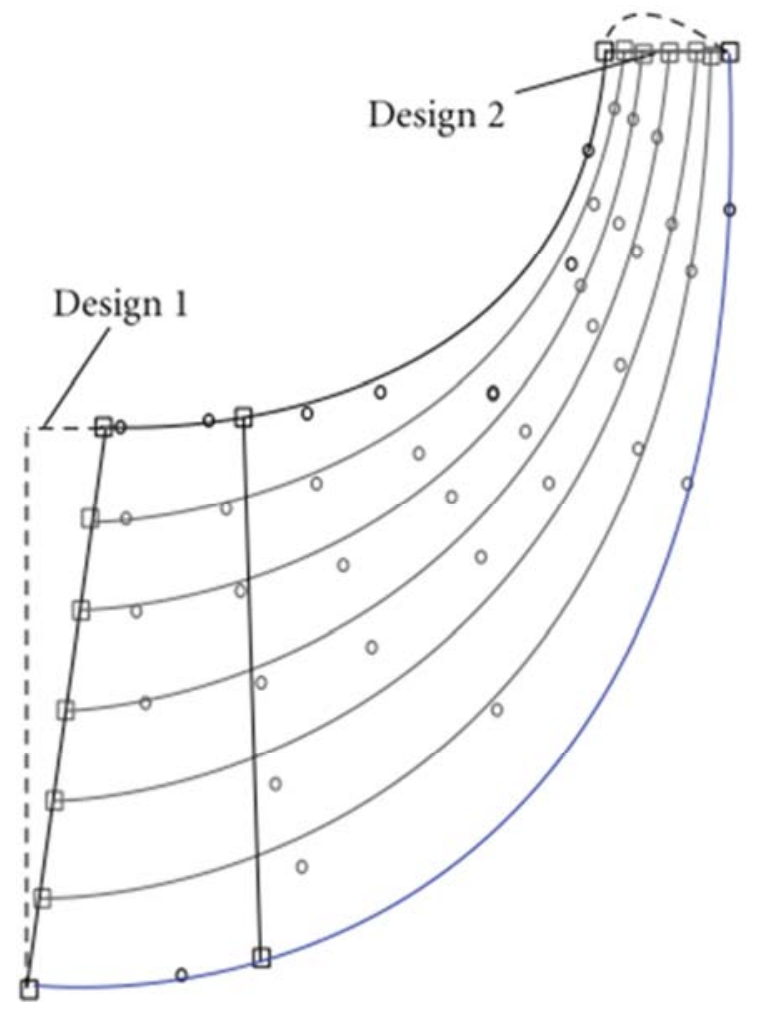

Figure 5. Meridional view of the two designs.

The research of blade thickness distribution of impellers in the academic circles is rather little. At present, the blade thickness of a centrifugal compressor impeller is arbitrary. The shape of blade pressure surface and suction surface is decided by blade thickness, for the defined blade camber, and the blade thickness greatly influences the flow field condition in the flow passage to a large extent. Therefore, adjusting and controlling the thickness distribution of the suction surface is the key point to improve the flow in the blade passage. Oana [8] studied the influence of the thickness distribution of rotary profile for the centrifugal compressor performance. The thickness distribution of pressure surface and suction surface has been given respectively. By adjusting the thickness distribution of the suction surface, the curvature of the suction surface after the arc length is reduced by $50 \%$ and a new blade profile is obtained. The numerical results show that the load at the blade root is reduced, and the low-energy fluid on the main blade and the splitter blade is effectively controlled at the outlet of the impeller. Chen [4] studied the influence of root blade thickness distribution on impeller flow. He gave four leaf root thickness distributions and analyzed the flow field respectively. The thickness distribution of suction surface inlet section should be balanced between decreasing local acceleration and decreasing blade root pressure to weaken secondary flow on the suction surface, The thickness distribution of the rear part of the suction surface and the pressure surface should avoid local acceleration and ensure the continuous increase of the surface pressure.

\subsection{Diffuser}

The diffuser of the centrifugal compressor mainly makes the airflow with large speed from the impeller to slow down so that the kinetic energy can be effectively converted into pressure energy. And the diffusers are the second important aerodynamic component in the centrifugal compressor. The insight flow of the diffuser is more difficult than the impeller because the inlet flow field of diffuser is influenced by the upstream impeller outlet flow field and interaction of impeller and diffuser. In terms of the different structure, the diffuser can be divided into vaned diffuser, vaneless diffuser. In general, a vaneless diffuser has the widest range of flow efficiency because there are no vanes to interfere with the flow when the gas passes through the diffuser. However, in the vaned diffuser, the gas must flow in the direction of the blade, so the peak attainable efficiency of the vaned diffuser is highest compared with vaneless diffuser. In recent years, unsteady calculation is becoming more and more mature, with the development of CFD software, and the research on diffuser is very active internationally. All of them are considering combining the merit of both two kinds of diffuser. Next, the research status of diffusers with different structures will be introduced.

The vaned diffuser is composed of a sheet of equal thickness or an airfoil blade and forces the airflow through the channel of a given geometry to achieve effective expanding of pressure. In the vaned diffuser, the law of mass conservation still applies, but different shapes of diffuser blades have different effects in expanding pressure. In recent years, there are many researches on the blade modeling of vaned diffusers. 
Tushar Goel [9] et al. designed the shape of the diffuser vane using a combination of the Bezier curves and a circular arc to improve the performance of diffuser, which is shown at figure 6. They used a surrogate model based optimization strategy to identify regions of the vane that have a strong influence on its performance. Optimization of the vane shape, in the absence of manufacturing and stress constraints, led to a nearly $8 \%$ reduction in the total pressure losses compared to the baseline design by reducing the base separation. Gunadal [10] studied numerically the effect of the leaned vanes in the low solidity vaned diffuser on the stable operating range of a centrifugal compressor. The vanes in the low solidity vaned diffuser were leaned in the direction of impeller rotation by reducing their inlet angle from hub to shroud uniformly. In his thesis, he numerically simulated diffusers from four different leaned vane angles. And they found that the compressor stage with $6^{\circ}$ leaned vaned diffuser gave an improvement of $19.3 \%$ and $12.2 \%$ in the stall margin and the operating range, respectively, over the stage with low solidity vaned diffuser. This research can improve the efficiencies near the stall margin which is likely to reduce the life cycle cost of the industrial centrifugal compressors. The double-row cascade diffusers is also a hot research point, as the layout form is shown in figure 8 . In order to reduce the growth of the boundary layer and prevent the airflow from detaching from the wall, the control technology of the boundary layer is used to disconnect the blade where the airflow may detach, and the diffuser blade is staggered for a certain distance in the circumference direction. Xie [11] is used to study the performance of centrifugal compressor splitter diffuser. The study concluded that double-row cascade diffusers can effectively prevent or delay the separation of flow, reduce the loss and improve the efficiency. And it also can reduce the velocity gradient in the low-speed zone inside the impeller, delay the occurrence of critical working conditions, and thus expand the compressor's working range. But the shape of the blade and the truncation position have great influence on its performance. This study indicate that the double-row cascade diffuser is worth further study.

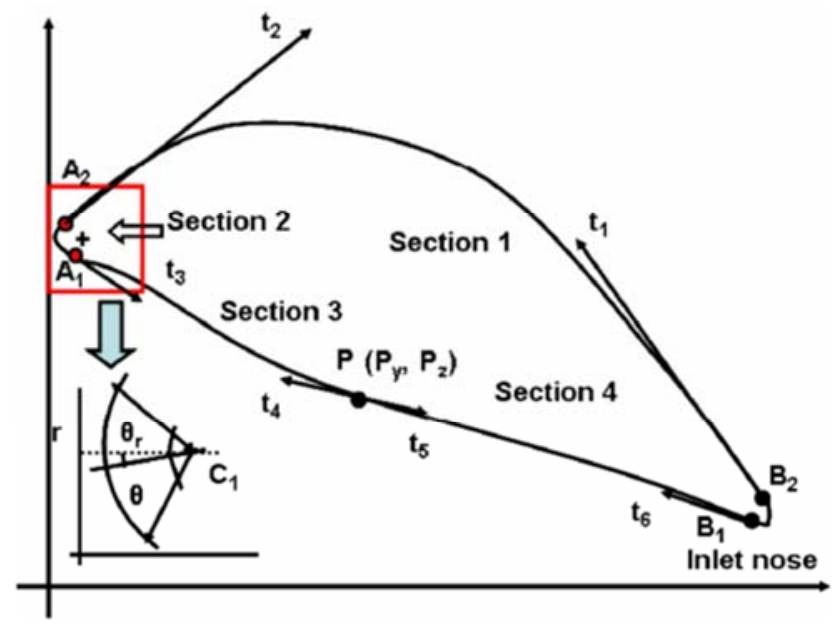

Figure 6. Definition of the geometry of the diffuser vane.
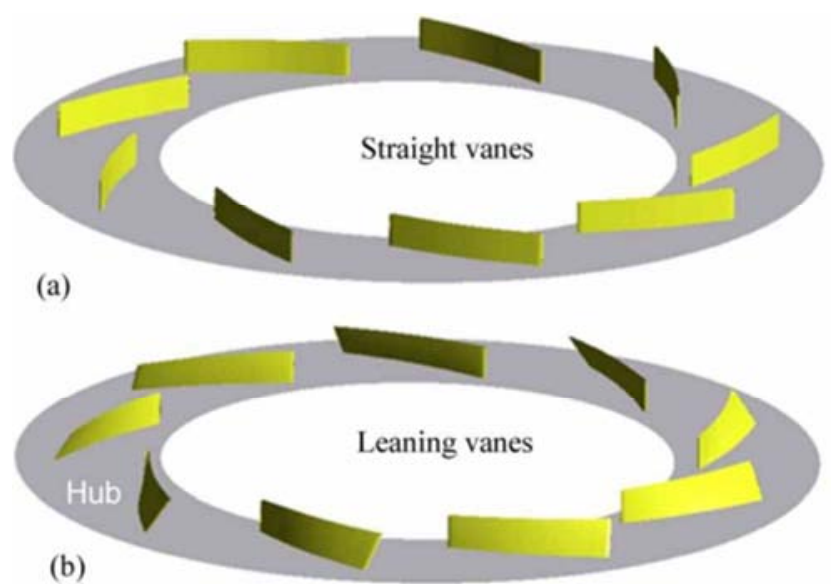

Figure 7. (a) Straight (b) Leaned vane in a diffuser.

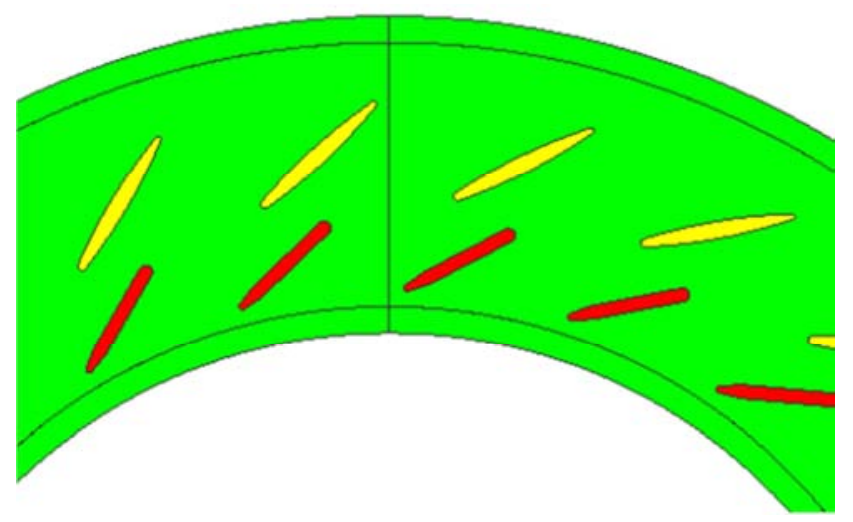

Figure 8. Double-row cascade diffuser.

The vaneless diffuser in early centrifugal compressors is widely used because of its advantages such as the wide range of variable working conditions and simple processing. The internal flow and performance of a vaneless diffuser depends entirely on its inlet flow parameters and the geometry and size of the diffuser. Thus the inlet flow conditions and geometric shapes are the dominant research area. Galerkin [12] developed a new primary design method of vaneless diffuser, which is called VLD initial design. And a new approach to the choice of rational relative width of the vaneless diffusers is proposed. At the border of surge the problem of flow angle control in the diffuser is solved. Recommendations on the choice of vaneless diffusers radial length are proposed. Vaneless diffuser can be divided into three types: parallel wall type, convergence type and expansion type. However, the effects of convergence type and expansion type on diffuser performance are not completely clear. Dou [13, 14] concluded the selection rules of vaneless diffusers under different fluid conditions and different wall inclination angles in the paper. The expanded diffuser is only suitable for the condition of large inlet flow Angle and high dynamic pressure, while the convergent diffuser increases the flow angle, makes the flow more uniform and reduces the loss in the flow channel which is beneficial for increasing the surge limit. The paper also raised the effect of diffuser wall surface changing on other components in the stage should be considered to optimize the performance of the whole stage. The narrowing of the 
vaneless diffuser after the impeller exit, which is called a pinch, is an important feature that requires further investigation. An excellent pinch design can improve the stall margin and thus a wider operating range. Ahti Jaatinen-Värri [15] did the research on the effects of the diffuser width on the flow fields in the vaneless diffuser of a centrifugal compressor and the schematic designs are shown in figure 9. According to the simulation and experimental data in the paper, a moderate pinch $\left(b / b_{2}=0.85-0.91\right)$ can decrease the high entropy/high loss areas associated with tip-clearance flow and also decreases the backflow from the diffuser into impeller near the shroud. But excessive pinches will cause reverse effects and lose the benefits of the pinch. And the paper indicated that width reductions up to $20 \%$ were beneficial.

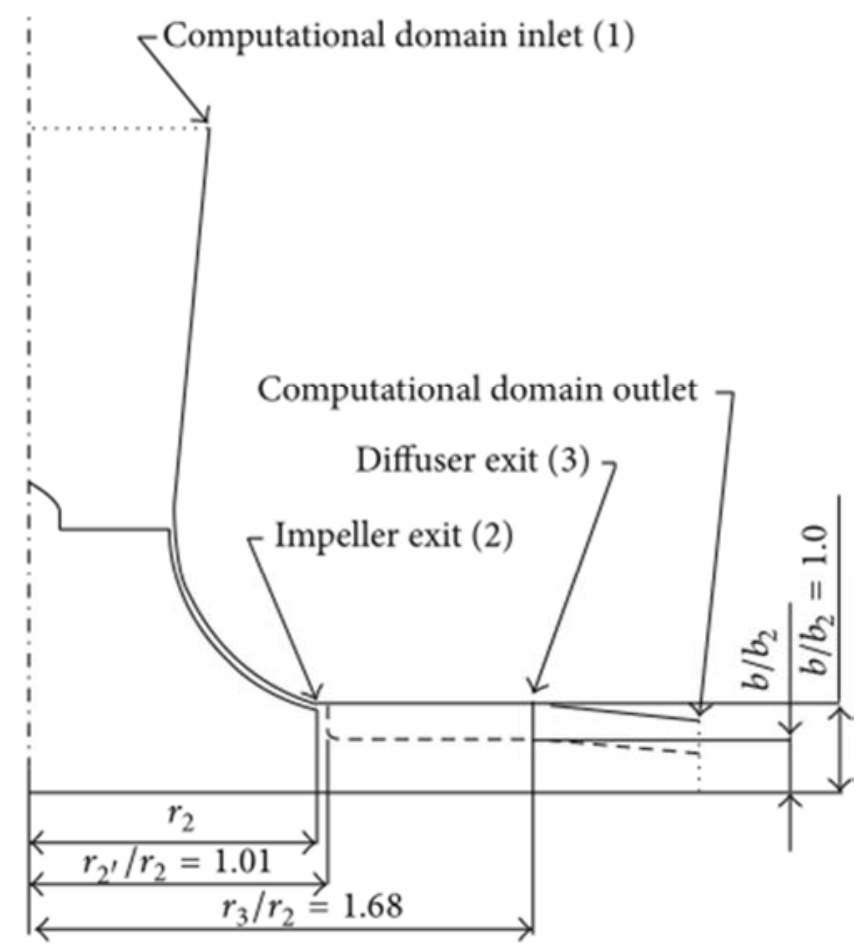

Figure 9. Schematic designs of the unpinched line (solid line) and pinched line (dashed line).

\subsection{Volute}

The gas still has a high velocity after passing through the impeller, diffuser and the function of volute is to collect and diffuse the air and make full use of the kinetic energy of the airflow to increase the pressure. Another important function of volute is to ensure that the impeller works in the uniform axisymmetric environment. The volute has a direct influence on the total efficiency and stability of the compressor. And little research of volute design optimization has been done. Most studies are focused on the volute shell structure parameters, and volute cross-sectional shape, etc.

Main volute shell structure parameters are the ratio of area to radius $(\mathrm{A} / \mathrm{R})$ and the diffuser inlet diameter. The $\mathrm{A} / \mathrm{R}$ is described in figure 10. Dong [16] obtained some conclusions by comparing volutes with different $\mathrm{A} / \mathrm{R}$ and diffuser inlet diameters. The paper indicated that increasing the $A / R$ and diffuser inlet diameter of the compressor volute can improve the charging ratio, flow rate and adiabatic efficiency of the compressor and also can make the surge boundary and the blocking boundary of the compressor to the direction of large flow. However, the blocking boundary offset is obviously greater than the surge boundary offset. There is a guidance of the Structural parameter design of the centrifugal compressor volute. The so-called "tongue" of volute is located at the joint of the volute smallest area, largest area and discharge location. At the position of the volute tongue, the fluid in the volute encounters a separation surface. Above the tongue, the fluid leaves the compressor and below the tongue, the fluid enters the volute. $\mathrm{Xu}$ [17] discussed the influence of different types of tongues for the diffuser flow field and centrifugal compressor total performance in the paper. The analysis data obtained from the paper shows the round tongue creates significant blockage near the tongue and the secondary flow center away from the tongue area due to the blockage. The secondary flow vector at sections $\theta=180^{\circ}$ and $\theta=360^{\circ}$ for both sharp and round tongues are shown in figures 11 and 12 . The results of research indicated that round tongue could improve off-design performance and eliminate unbalanced aerodynamic force. A large cut back tongue volute [18] is discussed to eliminate the circumferential distortion flow characteristics inside the stationary frame of a high-pressure ratio compressor at impeller exit. The round tongue changed head coefficients of the compressor stages. Different tongue radius has different impacts for compressor head coefficients which is shown in figure 13. Computed static pressure distributions at vaned diffuser exit and impeller exit at $\varphi / \varphi 0=0.7$ and 1.25 respectively are shown in figures 14 and 15 . Results showed that only small unsymmetrical static pressure could be seen at vaned diffuser exit for both flow conditions. However, pressure distortions were eliminated for both low flow and high flow cases at impeller exit.

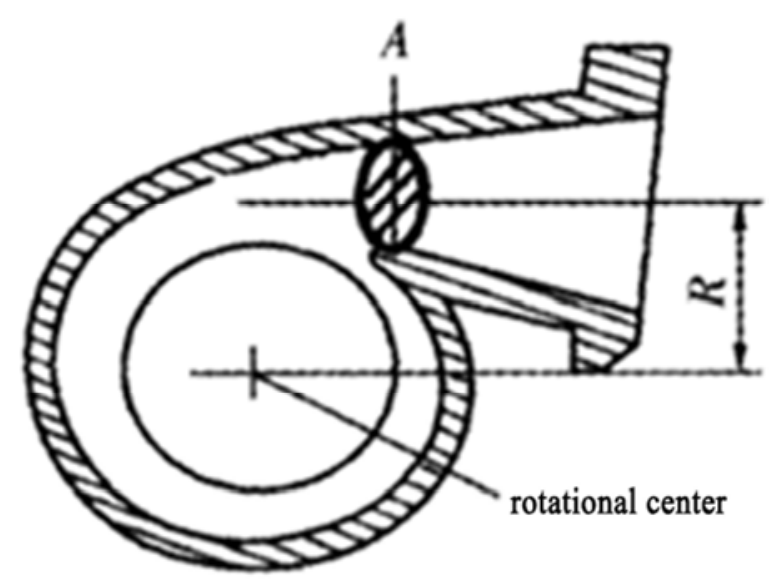

Figure 10. A/R of the centrifugal compressor volute. 


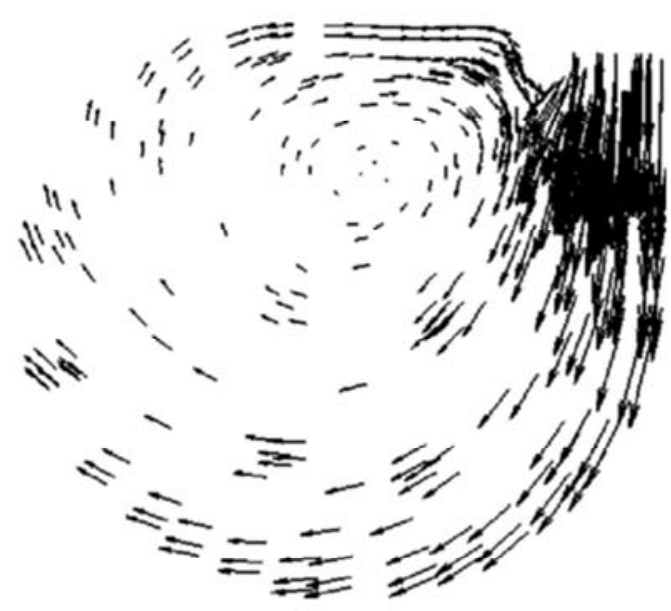

(a)

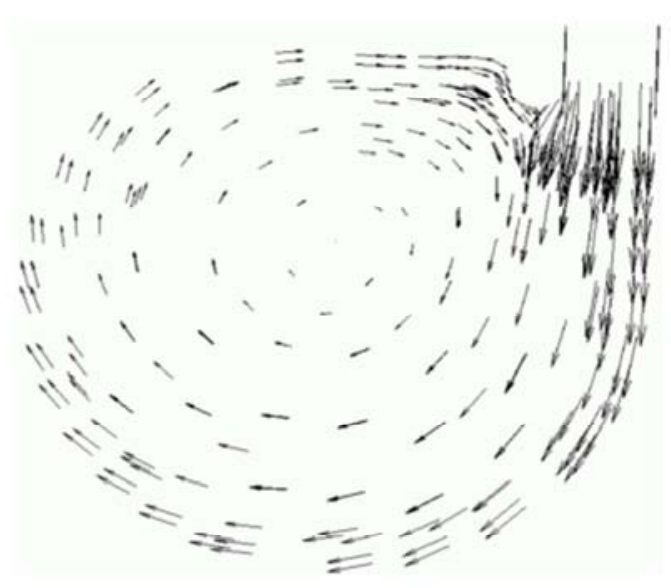

(b)

Figure 11. The velocity vectors versus the volute exit $\left(\theta=180^{\circ}\right.$ ) (a) sharp tongue. (b) round tongues.

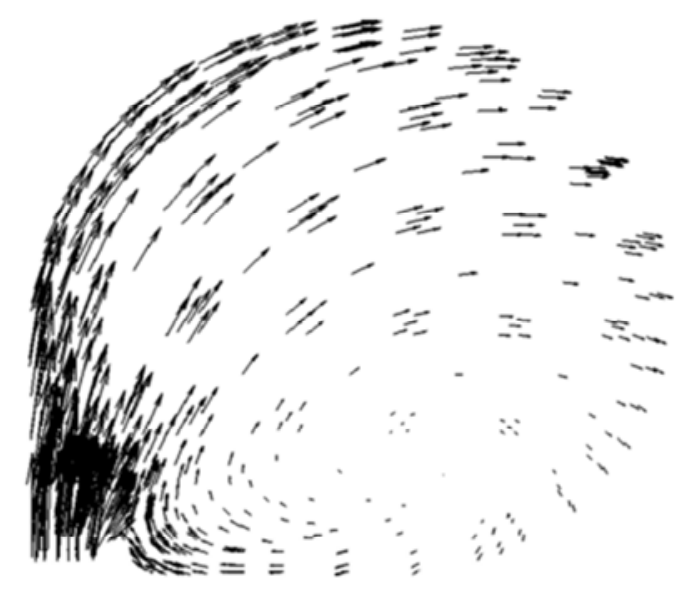

(a)

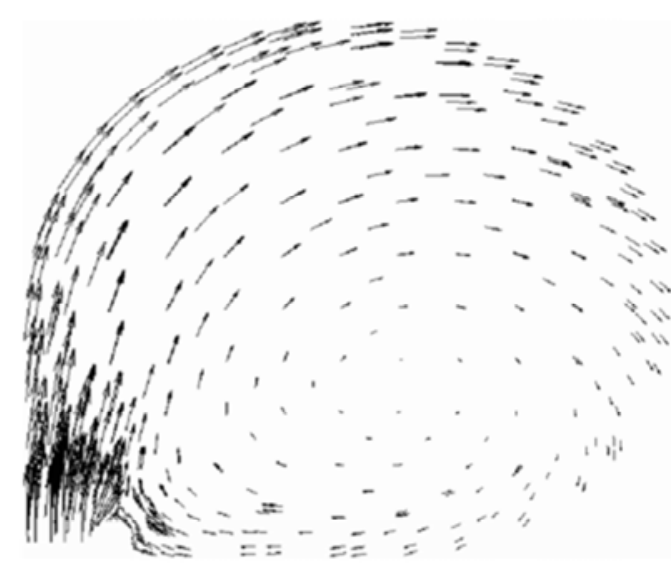

(b)

Figure 12. The velocity vectors versus the volute exit $\left(\theta=360^{\circ}\right)$ (b) sharp tongue. (b) round tongues.

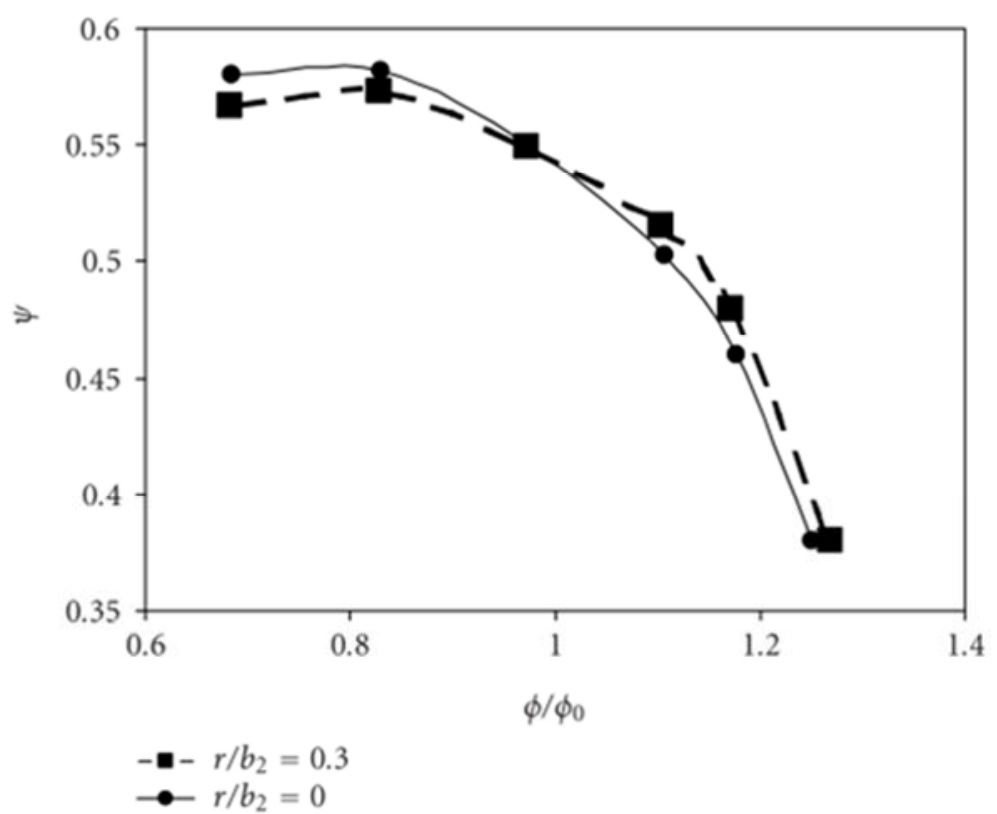

Figure 13. Volute tongue radius versus performance. 


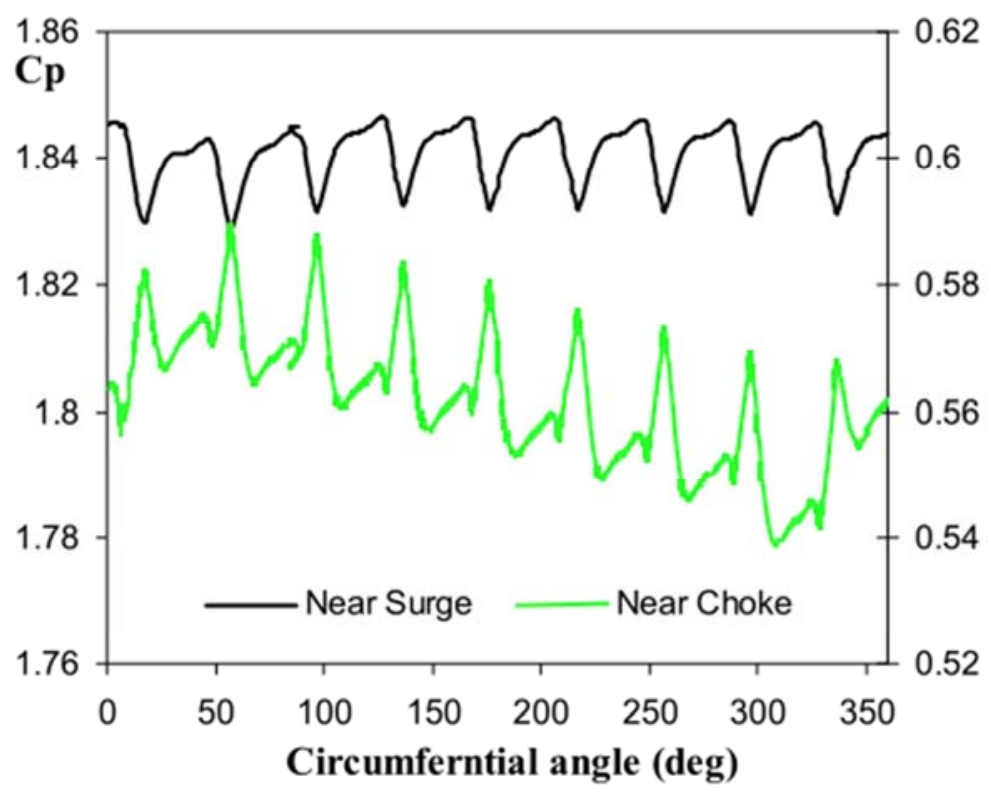

Figure 14. Static pressure coefficient at diffuser exit on the hub wall.

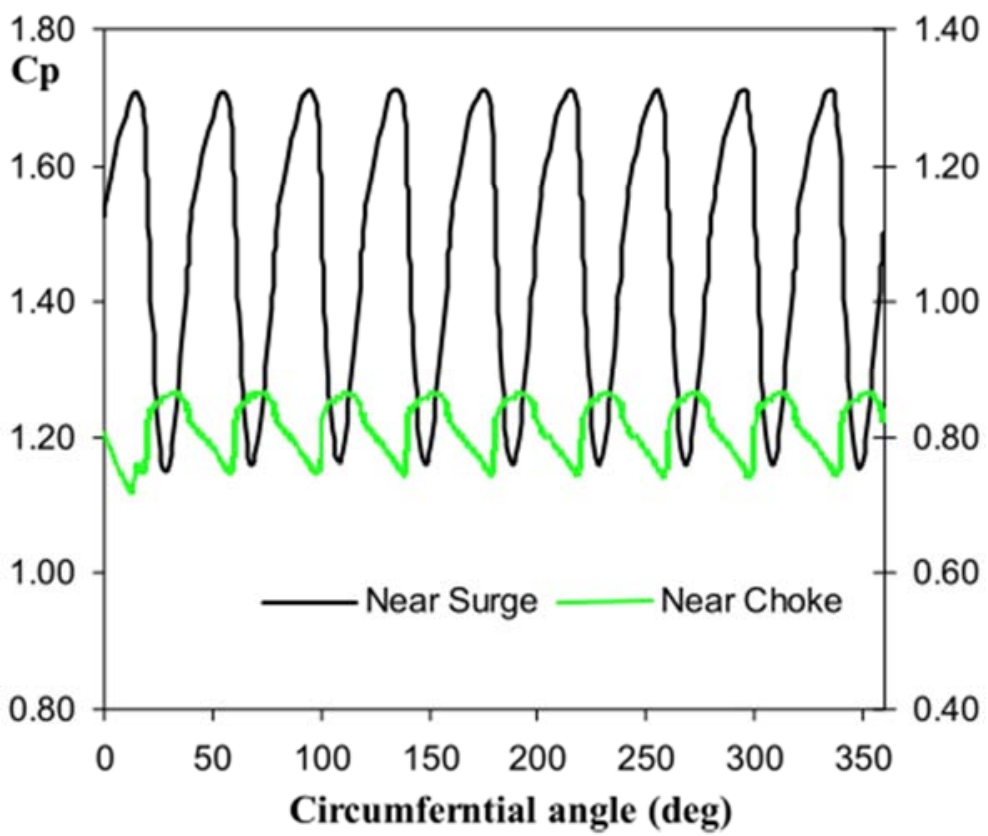

$\left(\phi / \phi_{0}=0.7\right.$ and 1.25$)$

Figure 15. Static pressure coefficient at diffuser exit at the hub wall.

\section{Summary and Conclusions}

At present, the design of the centrifugal compressor has already reached a very high level. The overall efficiency of the centrifugal compressor is already very high. But the factors that determine the efficiency are not only the impeller, but also the diffuser, volute and so on. Therefore, in order to further improve the performance of the centrifugal compressor, both design methods of the parts and integral optimization methods need to be developed. Some new topics are being explored, such as the interaction between impeller and diffuser $[19,20$, $21]$, the study on impeller, diffuser and volute as a whole [22] and so on. These research methods open up a new way to design more efficient centrifugal compressors.

In closing, the industry has not reached the end of the evolutionary process for centrifugal turbomachinery. Greater efficiency and wider operating range of centrifugal compressors are waiting for the researchers to explore.

\section{References}

[1] Xu, Cheng, et al. "The Development of an Integrally Geared Centrifugal Compressor." International Journal of Fluid Mechanics \& Thermal Sciences 5.1 (2019): 1. 
[2] Bonaiuti, Duccio, et al. "Analysis and optimization of transonic centrifugal compressor impellers using the design of experiments technique." J. Turbomach. 128.4 (2006): 786-797.

[3] Kim, S., J. Park, and J. Baek. "A numerical study of the effects of blade angle distribution on the performance and loss generation of centrifugal compressor impellers." Proceedings of the Institution of Mechanical Engineers, Part A: Journal of Power and Energy 226.2 (2012): 208-217.

[4] Chen Jie, "Research on Transonic Mciro Compressor Design Method.". Diss. Nanjing University of Aeronautics and Astronautics, 2010. (in Chinese).

[5] Wang Jianhua. "Design of flow path of blade wheel based on b-spline curve. " Journal of Yangtze University (Nat Sci Edit). 04: 10-11+113-116. (in Chinese).

[6] Wang Jianhua. "Design of flow path based on rational Bezier curve of centrifugal pump blade." Coal Mine Mechinery. 10 (2010): 29-31. (in Chinese).

[7] Xu, C., and R. S. Amano. "Meridional considerations of the centrifugal compressor development." International Journal of Rotating Machinery 2012 (2012).

[8] Oana, Mineyasu, et al. "Approach to high performance transonic centrifugal compressor." 38th AIAA/ASME/SAE/ASEE Joint Propulsion Conference \& Exhibit. 2002.

[9] Goel, Tushar, et al. "Improving the hydrodynamic performance of diffuser vanes via shape optimization." Computers \& fluids 37.6 (2008): 705-723.

[10] Gunadal, S. M., and M. Govardhan. "Improvement in stable operating range of a centrifugal compressor with leaned diffuser vanes." Journal of Mechanical Science and Technology 33.11 (2019): 5261-5269.

[11] Xie Rong, et al. "Study on the Performance of Staggered Cascade Diffuser in Centrifugal Compressor." Gas Turbine Technology. 23.2 (2010): 48-52. (in Chinese).

[12] Galerkin, Yu B., A. F. Rekstin, and O. A. Solovyeva. "Vaneless diffuser of the centrifugal compressor stage design method." AIP Conference Proceedings. Vol. 2141. No. 1. AIP Publishing LLC, 2019.

[13] Dou Huashu. "Design Principle of Radial Vaneless Diffuser with Non-Parallel Wall." Fluid Mechinery. 3 (1990): 15-19. (in chinese)

[14] Wu Huanbo, et al. "Study on the Performance of Non-Parallel Wall Vaneless Diffuser." Chinese Journal of Applied Mechanics. 02 (1988): 67-76+132-133. (in Chinese).

[15] Jaatinenvarri, Ahti, et al. "Investigation of the Stage Performance and Flow Fields in a Centrifugal Compressor with a Vaneless Diffuser." International Journal of Rotating Machinery (2014): 1-10.

[16] Dong Surong, et al. " Influence of Structural Parameters of Volute on Performance of Centrifugal Compressor " Automotive Engineering. 00.010 (2015): 41-43. (in Chinese).

[17] Xu, Cheng, and Michael Muller. "Development and Design of a Centrifugal Compressor Volute." International Journal of Rotating Machinery 2005. 3 (2005): 190-196.

[18] Xu, C. and R. S. Amano. "Eliminating Static Pressure Distortion by a Large Cut Back Tongue Volute." ASME Turbo Expo 2006: Power for Land, Sea, and Air 2006.

[19] Liu Yangwei. "Numerical investigation of impeller-diffuser interaction in a centrifugal compressor." Journal of Aerospace Power. 024.012 (2009): 2695-2702. (in Chinese).

[20] Anish, S., and N. Sitaram. "Computational study of radial gap effect between impeller and diffuser on the unsteadiness of vaned diffuser in a centrifugal compressor." Journal of Mechanical Science and Technology 31.11 (2017): 5291-5298.

[21] BONCINELLI., et al. "Impeller-diffuser interaction in centrifugal compressors: Numerical analysis of radiver test case." Journal of Propulsion \& Power 23.6 (2012): 1304-1312.

[22] Steglich, T., et al. "Improved Diffuser/Volute Combinations for centrifugal Compressors." Journal of Turbomachinery 130.1 (2008). 